\title{
EMPREGABILIDADE E INSERÇÃO SOCIAL DOS JOVENS COMO DESAFIOS PARA A EDUCAÇÃO PROFISSIONAL E TECNOLÓGICA
}

\author{
Employability and social inclusion of young people \\ as challenges for professional and technological education
}

\begin{abstract}
RESUMo Associada à pedagogia das competências e à submissão à teoria do capital humano, a educação passou a ser considerada a chave para a empregabilidade. $O$ aumento quantitativo da oferta de educação profissional e tecnológica tem sido objeto constante de discussão e reflexão, no sentido de estabelecer mecanismos de oferta e medidas de avaliação da formação profissional, objetivando respostas satisfatórias nos quesitos de qualidade, tanto para as comunidades inseridas no meio social, quanto para o setor produtivo. Neste estudo, a partir de pesquisa bibliográfica e documental, analisa-se a aderência ou não da educação profissional e tecnológica a esse desiderato, considerando, igualmente, os estudos que contextualizam e problematizam o conceito de empregabilidade atrelado ao conceito de competência.
\end{abstract}

PALAVRAS-CHAVE: EduCAÇÃo E TRABALHO. EdUCAÇÃO PROFISSIONAL E TECNOLÓGICA. JUVENTUDE, TRABALHO E EDUCAÇÃO.

ABSTRACT Associated with the pedagogy of skills, submission to the theory of human capital, education come to be considered the key to employability. The quantitative increase in the offer of vocational and technological education has been a constant subject of discussion and reflection, in order to establish mechanisms of supply and measures of evaluation of vocational training, aiming for satisfactory answers in the quality requirements, both for inserted communities in the social environment and for the productive sector. In this study, based on bibliographical and documentary research, it is analyzed the adherence or not of professional and technological education to this desiderato, also considering the studies that contextualize and problematize the concept of employability linked to the concept of competence.

Keywords: EDUCATION AND WORK. PROFESSIONAL AND TECHNOLOGICAL EDUCATION. YOUTH, WORK AND EDUCATION.

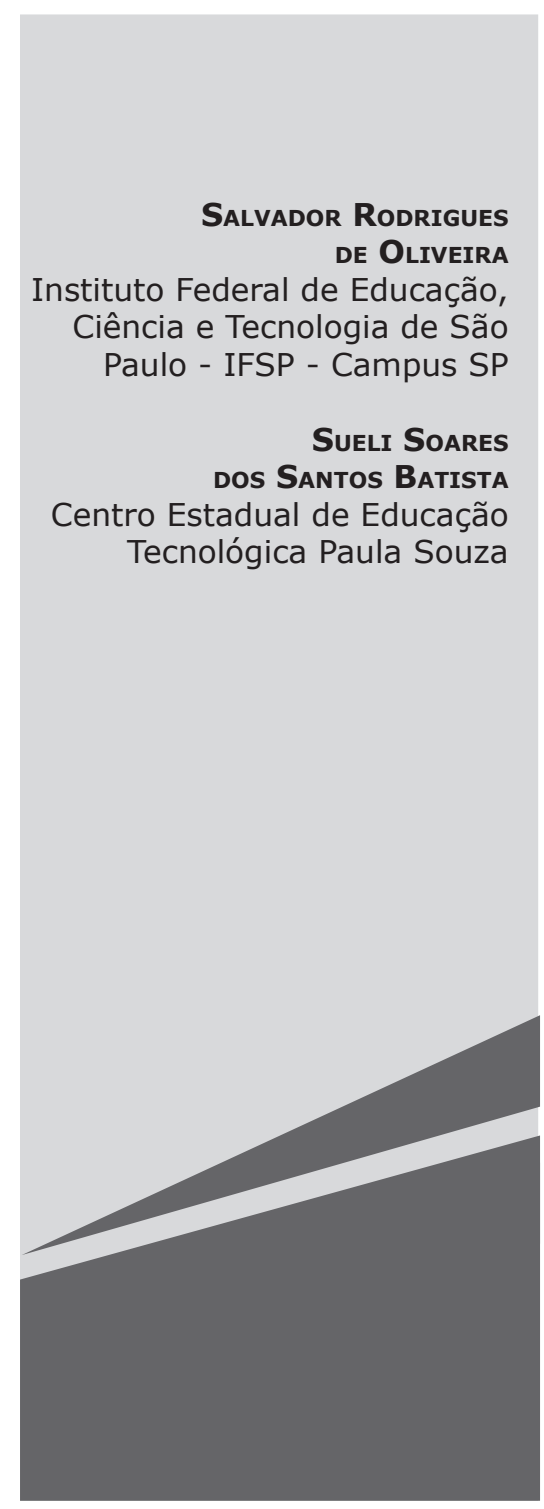




\section{INTRODUÇÃO}

C

om a reestruturação produtiva em curso, a partir dos anos 1970 e 1980 e para acompanhar o dinamismo na produção e se tornarem competitivas, muitas empresas passaram a exigir pessoas detentoras de competências e habilidades, com características de polivalência. Segundo Helal (2005) e Helal e Rocha (2011), a atual conjuntura do mercado de trabalho é consequência do processo de reestruturação da economia iniciada nesse período, devido ao enfraquecimento do modelo fordista de produção. Diante deste novo contexto social, surgiu a inquietação com a empregabilidade e novas exigências foram feitas aos trabalhadores, por parte das organizações, tendo como respaldo o novo modo de concentração capitalista, o pós-fordismo alinhado aos interesses do neoliberalismo internacional.

Essa mudança ocorreu em função do aumento da competitividade dos mercados, bem como, das mudanças nas tecnologias em espaços temporais cada vez menores. A reestruturação produtiva fez com que muitas funções dentro das organizações fossem destituídas, assim como outras emergiram. A inovação na tecnologia resultou no fechamento de muitos postos de trabalhos, sobretudo no setor industrial, enquanto houve expansão no setor de serviços. Devido à flexibilização das relações trabalhistas no mercado formal de trabalho, muitos empregos se tornaram precários, aumentando o número de empregos autônomos e o trabalho informal de modo geral (BRUNO, 1996; HELAL, 2005).

Para Helal (2005), assim fortaleceu-se a exigência de algumas características para tornar uma pessoa empregável. Associada à pedagogia das competências e à submissão à teoria do capital humano, a educação passou a ser considerada a chave para a empregabilidade.

Agilidade, disposição para trabalhar em ambientes de mudanças e de incertezas, capacidade de assumir riscos perenemente, flexibilidade em relação às novas determina- ções do mercado, possibilidade de lidar com situações inusitadas, entre outras aparecem neste cenário, como competências desejáveis aos indivíduos para que não só obtenham emprego, mas, para que consigam permanecer empregados e empregáveis a maior parte do tempo, evitando-se, assim, o desemprego permanente.

Neste estudo, a partir de pesquisa bibliográfica e documental, analisa-se a aderência ou não da educação profissional e tecnológica a esse desiderato, considerando, igualmente, os estudos que contextualizam e problematizam o conceito de empregabilidade atrelado ao conceito de competência.

\section{DESENVOLVIMENTO DE COMPETÊNCIAS PARA A EMPREGABILIDADE NAS INSTITUI- ÇÕES DE ENSINO: A NECESSIDADE DE ES- TUDOS SOBRE EGRESSOS}

Segundo Oliveira e Mañas (2004), as formas de trabalho têm passado por fortes transformações e redefinições e embora o emprego não tenha desaparecido, este pode deixar de existir da forma como é compreendido. Os conceitos de competência e empregabilidade são, na verdade, requisitos para adequações de pessoas ao trabalho. $O$ trabalhador deve estar em luta constante para se aperfeiçoar e se atualizar profissionalmente visando continuar no emprego ou para conseguir outro, por meio de sua capacitação (BETTIOL, 2009).

Esse cenário está fortemente alinhado com as diretrizes do Banco Mundial nos anos 1990, a partir das quais a ênfase no papel da escolarização ganhou espaço nos debates educacionais e nas políticas públicas, com assento em processos de profissionalização na perspectiva deste tipo de formação para o trabalho que passou a ser demandada. $\mathrm{Na}$ análise de Oliveira (2001):

A preocupação do Banco Mundial com a educação profissionalizante justifica-se, dentre outros fatores, pela necessidade das economias em desenvolvimento disporem de 
uma mão-de-obra flexível, capaz de adequar-se às mudanças ocorridas no mundo do trabalho. Para o Banco Mundial, o investimento na qualificação dos trabalhadores é tão necessário quanto o maior investimento de capitais em áreas fundamentais ao desenvolvimento econômico. Para as economias em desenvolvimento atingirem um maior nível de competitividade no cenário internacional, o Banco Mundial recomenda ações que conjuguem esforços de vários setores da sociedade no processo de qualificação profissional. Deve haver uma participação do poder público e da iniciativa privada no desenvolvimento de melhores estratégias que garantam aos trabalhadores maior aptidão para acompanharem as mudanças atuais (OLIVEIRA, 2001, p. 1).

$\mathrm{Na}$ conjuntura atual há, ainda, discussões propondo a flexibilização das relações das condições de trabalho, o que pode tornar mais precária a situação do trabalhador. Assim, a defesa da empregabilidade tem sido utilizada, no contexto da reestruturação produtiva, como uma das herdeiras da teoria do capital humano frente à modernização tecnológica para a qual precisaria de qualificação profissional permanente dos trabalhadores (BALASSIANO; SEABRA; LEMOS, 2005).

Para Bettiol (2009), dessa forma, com o conceito de empregabilidade, impõe-se ao trabalhador uma (re) qualificação continuada, como seu dever e responsabilidade. De acordo com essa concepção, as pessoas são responsáveis individualmente por colocarem-se em condições empregáveis. Porém, há outras variáveis que podem determinar, ou não, a inserção de uma pessoa no mundo do trabaIho como, por exemplo, o cenário econômico instalado no país, se há ou não estímulo do poder público para a geração de emprego, entre outras. Tais questões não são levadas em consideração e a responsabilidade recai unicamente sobre o trabalhador, devendo este ser um empreendedor de sua própria capacitação e aquisição de competências. Dentro desta lógica, a sociedade e o Estado transferem suas responsabilidades ao trabaIhador. O investimento em capital humano, para atender os requisitos da reestruturação do setor produtivo, passa a ser sua obrigação (OLIVEIRA, 2017).

Helal, Neves e Fernandes (2009), em um estudo dobre empregabilidade, constataram que as organizações estão atribuindo mais valores às competências do que às qualificações técnicas. Ter habilidades técnicas não é mais o suficiente, uma vez que é essencial que o trabalhador tenha conhecimento generalista (polivalente funcional) e seja detentor de criatividade, capacidade de trabalhar em grupo e de autogestão.

Essa nova gestão do trabalho e dos trabalhadores está ancorada, segundo Deluiz (2001), numa lógica de recomposição da hegemonia capitalista e das relações capital-trabalho, tendo como objetivos racionalizar, otimizar e adequar a força de trabalho face às demandas do sistema produtivo. A ideia de competência, a partir dos anos 1990, é incorporada à prática organizacional num "[...] alinhamento definitivo das políticas de recursos humanos às estratégias empresariais" (p. 1)

Helal e Rocha, em 2011, publicaram um trabalho com a temática da empregabilidade, tendo como propósito melhor compreender o pensamento da academia e do meio empresarial a respeito disso. Aborda-se aqui um dos aspectos do estudo realizado quando este se atenta a diferentes tipos de publicação que se dedicaram ao tema da empregabilidade. O estudo teve um recorte de publicações realizadas de janeiro de 1997 a julho de 2007 . Foram selecionados para a análise apenas os artigos com maior nível de aprofundamento na abordagem da empregabilidade. Feita a seleção, o universo pesquisado resultou num total de 45 artigos, sendo 19 acadêmicos e 26 não acadêmicos.

Dois tipos - identificados como grupos 
"A" (artigos obtidos na base Scielo) e "B" (RAC e Enanpads) - são referentes a publicações acadêmicas. Foram analisadas, ainda, as publicações de uma revista especializada em recursos humanos (Você S/A) e também de um jornal de grande circulação (Folha de São Paulo).

Os autores levaram em conta o estudo da empregabilidade, a partir das publicações selecionadas no período preestabelecido, criando, inicialmente, duas categorias de análise: a visão crítica-social e a visão empresarial-individual. A visão crítica-social, segundo os autores, é aquela que trata "a empregabilidade como um discurso, transferindo a responsabilidade pelo emprego da sociedade e do Estado para o próprio trabalhador" (p. 144). A visão empresarial é definida como aquela que considera "a empregabilidade como a capacidade de adaptação da mão de obra [do indivíduo] às novas exigências do mundo do trabaIho e das organizações" (p. 144). Os autores também identificaram que essas categorizações deixam escapar uma perspectiva híbrida da empregabilidade. Esse levantamento pode ser visualizado na Tabela 1.

Os autores concluíram que a Revista Você S/A tem uma visão completamente empresarial sobre a empregabilidade, enquanto o Jornal Folha de São Paulo caminha para um pensamento mais crítico e consciente demonstrando uma mudança de perspectiva em algumas publicações de massa. Como já era esperado, os estudos de caráter científico e conceitual se mostraram mais enquadráveis na categoria crítica, embora os autores tenham identificado que a preocupação com essa temática se mostrou recente, surgindo artigos abordando o assunto a partir de 2004. A visão empresarial ou híbrida não deixou de aparecer nos periódicos acadêmicos selecionados, sendo esse dado um elemento importante para perceber a apropriação pelas instituições de ensino da lógica que permeia as políticas educacionais voltadas à profissionalização. Esse é um dado interessante porque os sistemas de avaliação das instituições de ensino também estão alinhados com essa lógica, demandando estratégias institucionais que possam resultar em indicadores favoráveis em relação aos seus egressos.

As instituições de ensino do país estão sendo incentivadas a realizar estudos sobre os perfis dos seus egressos, como forma de contribuir com melhorias na qualidade e na oferta dos cursos; do mesmo modo contribuir para estabelecer estratégias que inovem e aprimorem continuamente o método de ensino utilizado, visando os pressupostos da competência e da empregabilidade (SAMPAIO et al., 2013).

Segundo Machado (2010), a avaliação, tanto externa quanto interna, dessas instituições pode oferecer subsídios às políticas institucionais, porque se leva em conta as contribuições das pessoas em diferentes contextos e situações, o que torna possível enxergar o horizonte em sua plenitude. Afirma que:

É de grande relevância saber o que os egressos pensam a respeito de sua formação, para que a Instituição possa proceder aos ajustes finos no seu sistema de ensino. Além disso,

Tabela 1 - Visões dos grupos de publicações acerca da empregabilidade

\begin{tabular}{l|c|c|c|c|}
\hline \multirow{2}{*}{ Categorias de análise } & \multicolumn{2}{|c|}{ Grupo Acadêmico } & \multicolumn{2}{c|}{ Grupo Empresarial } \\
\cline { 2 - 5 } & Grupo A & Grupo B & Revista de RH & Jornal \\
\hline Visão crítica & 9 & 4 & 0 & 13 \\
\hline Visão empresarial & 4 & 0 & 5 & 8 \\
\hline Visão híbrida & 2 & 0 & 0 & 0 \\
\hline Total & 15 & 4 & 5 & 21 \\
\hline
\end{tabular}

Fonte: Adaptada de Helal e Rocha (2011). 
conhecer o que fazem como profissionais, e suas adequações nos setores que atuam, possibilita uma reflexão crítica sobe a formação e sua relação com as necessidades do mercado de trabalho. Um adequado sistema de acompanhamento de egressos viabiliza inúmeras contribuições no sistema de alimentar as discussões sobre a aproximação da academia à realidade do mercado de trabalho (MACHADO, 2010, p. 44).

Machado (2010) realizou uma pesquisa sobre os egressos da Universidade Federal do Rio Grande do Sul (UFRGS), por meio do Portal de Egressos da Instituição, com cerca de sete mil cadastrados. Foi disponibilizado um questionário para ser respondido eletronicamente, no mês de setembro do ano de 2004. Além dos ex-alunos, também realizou-se uma pesquisa interna, no mesmo período, junto aos professores, técnicos administrativos e atores internos, de modo que os dados estatísticos fossem tratados contemplando um horizonte maior, ou seja, os aspectos internos e externos inerentes à UFRGS. A pesquisa abrangeu egressos de todos os cursos, níveis e modalidades de ensino da Instituição. No tratamento estatístico dos dados foi realizado um acompanhamento dos egressos ano a ano, a respeito das perspectivas, desejos e aspirações com relação à formação que receberam, com relação à Instituição de ensino, abarcando os egressos que se encontravam desempregados, os que estavam atuando fora da área de formação e os que obtiveram crescimento profissional dentro da área de formação (MACHADO, 2010).

Machado (2002), em outra pesquisa realizada, desta vez envolvendo os egressos do ensino técnico das Escolas Técnicas vinculadas à UFRGS, utilizou um questionário com perguntas fechadas para obter respostas e promover a discussão dos dados coletados e estes foram tratados estatisticamente. A pesquisa se desenvolveu por meio de um estudo de caso, que teve como objetivo verificar quais atributos, competências e habilidades eram demandados pelas empresas, em relação aos profissionais egressos dos cursos técnicos de nível médio. A pesquisa teve como norte obter uma opinião junto à Instituição de ensino, intencionando ajustar os conteúdos dos cursos técnicos, para melhor atender às necessidades das empresas localizadas na região, de maneira a haver maior integração entre a Instituição de Educação e o mercado de trabalho.

Outra estratégia sobre os estudos com egressos, citada por Machado (2002), seria promover uma avaliação que articulasse as perspectivas de professores, técnicos administrativos e da gestão, visando direcionar futuras reformulações na matriz curricular e nas metodologias de ensino dos cursos técnicos oferecidos, tendo como propósito, também, oferecer uma educação com competências e habilidades alinhadas com o mercado de trabalho e condizentes com as novas tecnologias.

Com base nessas preocupações Lemos, Dubeux e Soares Pinto (2009) realizaram outro estudo a partir de um questionário aplicado a 98 formandos e egressos do Curso Superior em Administração, de uma renomada Instituição de Ensino Superior particular do Estado do Rio de Janeiro. Composto por perguntas fechadas o questionário foi aplicado nos meses de março e abril de 2008. Após tratamento dos dados ficou constado que indivíduos oriundos de classes sociais mais elevadas tendem a ocupar postos de trabalho igualmente mais elevados, com maiores salários e com melhores condições de trabalho. Por outro lado, os indivíduos originários de famílias com menores rendas e filhos de pessoas com baixo grau de instrução tendem a ocupar postos de trabalhos menos atrativos, com menores salários e com condições de trabalho precárias, geralmente, em empresa de pequeno e médio porte. Esse estudo demonstra, entre outros fatores, que a origem familiar e social também está associada aos indicadores de empregabilidade dos egressos.

O que se observa é que os estudos sobre egressos, surgidos, em sua maioria, a partir 
dos anos 2000, procuram verificar a adequação da escola em diferentes níveis, com as demandas do mercado de trabalho, alinhando a efetividade desta formação com os indicadores de emprego. $O$ que se pretende aqui é buscar elementos para discutir o quanto a busca dessa efetividade tem seus limites e pode ser problemática como único elemento de análise sobre a inserção social dos estudantes, sobretudo, àqueles da educação profissional e tecnológica.

\section{JUVENTUDE, EMPREGABILIDADE E EDU- CAÇÃO PROFISSIONAL E TECNOLÓGICA}

Segundo Marciel (2006), o problema do desemprego atinge de forma mais sensível os jovens, pelo fato de nesta fase eles almejarem uma vida adulta com independência financeira e, como ainda não estão inseridos no mercado, costumam encontrar dificuldades por não terem experiência profissional. O problema do desemprego atinge muito diretamente os jovens, sobretudo, os oriundos de famílias de baixa renda, pelo fato de, muitas vezes, serem obrigados a se inserirem no mercado mais cedo, seja para ajudar no orçamento da família ou para adquirir recursos financeiros para custear um curso superior.

Para superar esses desafios muitos desses jovens optam por fazer um curso técnico, inclusive para viabilizar mais segurança em relação à garantia de emprego, que pode ser proporcionada pela formação profissional ainda na educação básica e como ponto de partida para continuar se aprimorando ou se aperfeiçoando profissionalmente.

A educação profissional tem sido tratada nos discursos governamentais, em diretrizes educacionais, bem como em estudos acadêmicos como relevante contribuição para tornar as pessoas empregáveis, de modo a promover a igualdade social. Para Marciel (2006), atrelando igualdade de oportunidades à empregabilidade,

A educação profissional surge como uma possível alternativa para a pro- dução de uma maior igualdade de oportunidades, contribuindo com a formação de um conjunto de trabalhadores qualificados para a execução de tarefas no setor urbano-industrial (MARCIEL, 2006, p.101).

Segundo Arcanjo et al. (2015), o contexto atual do Brasil tem requerido políticas públicas eficazes, direcionadas à formação de mão de obra técnica e tecnológica de qualidade e compatível para lidar com os avanços ocorridos a partir dos anos 1990 no campo técnico-científico, sobretudo, nas áreas da informação e da comunicação. Para esses autores a educação profissional técnica ou tecnológica deve ter como linha mestra a formação integral do indivíduo, com o objetivo de prepará-lo para o desenvolvimento de raciocínio crítico-reflexivo e para o exercício da vida cidadã. Esta formulação decorre dos avanços perseguidos e proclamados pelo Decreto Federal de $n^{\circ} .5 .154$, de 2004 (BRASIL, 2004). Os pressupostos anunciados nesse decreto almejam superar a reforma do ensino médio e profissional promovida pelo governo Fernando Henrique Cardoso, cujo objetivo prioritário era a melhoria da oferta educacional e sua adequação às novas demandas econômicas e sociais da sociedade globalizada, alinhando a preparação para o trabalho aos padrões de produtividade e competitividade vigentes (MEC, 2004).

As leituras predominantes das reformas educacionais dos anos 2000 foram fortemente marcadas por essa contraposição entre o Decreto $n^{\circ} 2.208$, de 1997 e o de $n^{\circ} 5.154$, de 2004. Para Souza (2015), a educação profissional e tecnológica foi tratada como grande prioridade na formação de agenda no Governo Lula (2003-2011), como expansão da Rede Federal, incentivos à educação profissional e reforma do ensino técnico por meio desse Decreto $n^{\circ}$ 5154/2004. A criação e interiorização dos Institutos Federais teriam, assim, contribuído significativamente para o projeto de desenvolvimento nacional; no entanto, o aparelhamento da política dependeu do que 
estava formulado como marco legal do governo anterior. Segundo esse autor, destacam-se neste cenário de políticas públicas voltadas à EPT, as propostas de redirecionamentos para a educação profissional com o propósito de garantir a democratização do acesso, inclusive por meio de incentivos, como as cotas para as populações de baixa renda aos cursos técnicos, visando assegurar a permanência dos jovens e adultos nos cursos de educação profissional.

Para Frigotto (2007) e Loponte (2006; 2010), a reforma da educação profissional de nível técnico, instituída pelo Decreto ${ }^{\circ} 2.208$, de 1997, foi realizada de maneira impositiva e inflexível, ou seja, não foram aceitas contribuições e nem o posicionamento de professores, gestores da educação, bem como, dos representantes da sociedade civil. O empenho maior se deu pelos do capitalismo internacional, com vistas a contratar mão de obra treinada para executar atividades especificas e para ocupar postos de trabalho dentro de grandes empresas.

Para Loponte (2010), a reforma na educação profissional de 2004, permitida por meio do Decreto $n^{\circ} 5.154$, tornou possível uma abordagem de conhecimento mais articulada e mais ampla, portanto, com mais qualidade. Tal reforma foi considerada um avanço para a educação profissional de nível técnico.

Cordão (2013) também asseverou que o poder público conjuntamente com a sociedade civil e as instituições de ensino deveria elaborar propostas de políticas públicas direcionadas à educação profissional, que levassem à construção de uma matriz curricular e à oferta de cursos que contribuam para a redução da dualidade entre a educação profissional e a educação propedêutica.

Peterossi (2014) afirma que diante da conjuntura atual, marcada pela expansão das redes de ensino técnico de nível médio, tornou-se essencial direcionar políticas para qualificação de recursos humanos e de valorização dos professores, para assegurar uma educação de qualidade diante da ampliação da oferta, que leve em consideração os aspec- tos e as especificidades relacionadas a procedimentos didáticos, pedagógicos, culturais e sociais do educando.

Entende-se, assim, de maneira quase consensual, que é preciso que os modelos de formação de professores da educação profissional sejam aprimorados a partir do estabelecimento, pelo poder público, de políticas públicas e incentivo cultural para que este docente seja referenciado como profissional com formação holística, capacitado e detentor de competência técnica, autonomia para atuar na educação profissional e ser um mediador na construção de conhecimentos. Isto considerando que dado o cenário político pós-2015 no Brasil, a expansão das redes públicas de escolas de EPT, mesmo que arrefecida, cumpre um papel central nas políticas educacionais.

Mas, conforme analisa Batista (2011) há que se estudar, sobretudo na educação profissional, o sentido ideológico da noção de competência, da empregabilidade, da laboralidade e do empreendedorismo, buscando a compreensão de como os mesmos foram incorporados pelas políticas públicas. O suposto consenso entre legisladores e pesquisadores se dá pela defesa da educação profissional com vistas ao desenvolvimento tecnológico, sendo essa defesa o cerne das propostas de ensino técnico integrado ao médio. Assim é que, colocando-se criticamente às reformas educacionais dos anos 90 com enfoque na educação profissional, o documento que deu suporte para o Decreto de 2004 estabeleceu que:

[...] as instituições com características de educação profissional e tecnológica, no quadro atual da concorrência capitalista dos processos produtivos, são conduzidas a considerar a dimensão da tecnologia repercutindo no processo de trabalho, bem como a produtividade dos trabalhadores. Isso deve ocorrer pela aquisição de novos conhecimentos técnicos e de habilidades, atitudes e comportamentos 
que induzem à iniciativa, gestão de processos, capacidade de agir em situações imprevistas e de modo cooperativo (MEC, 2004, p. 43).

Por outra via, ou seja, de maneira crítica à ideia simplista e à "[...] uma compreensão linear, que apenas treina o cidadão para a empregabilidade" (p. 4), as formulações deste documento caminham na mesma direção que tece criticas (mesmo ao evitar a palavra "competência"), ao não colocar em cheque as concepções de tecnologia, trabalho e produtividade dos trabalhadores no "quadro atual da concorrência capitalista". O que se afirma é que a crítica à ideia de competência é inseparável da crítica da ideia de empregabilidade e de produtividade do trabalho.

É a partir dos anos 2000, quando a reforma do ensino médio associada à reforma da educação profissional, que a crítica à ideia de competência se torna fundamental. Essa ideia já havia sido incorporada pelo Senai, Senac e outras instituições de EPT, além de estar marcadamente presente nos documentos e diretrizes do Ministério da Educação e dos programas do Ministério do Trabalho e Emprego. Mesmo que se considere que "[...] as competências se reduzem a uma parte dos atributos do trabalhador, não incluindo dimensões culturais e cognitivas fundamentais à avaliação das potencialidades dos sujeitos", esse discurso tem atravessado não só as propostas de educação profissional, mas a escolarização em todos os níveis, configurando-se como uma expansão designada por Dias (2015) como "espírito da profissionalização".

Neste sentido, é importante considerar a ideia de tecnologia que sustenta a suposta articulação entre educação profissional e tecnológica e que igualmente aparece nas diretrizes para o ensino médio. Na Resolução CNE/CEB de $n^{\circ}$. 2/2012, a tecnologia é conceituada como a transformação da ciência em força produtiva ou mediação do conhecimento científico, e a produção, marcada, desde sua origem, pelas relações sociais que a levaram a ser produzida (BRASIL, 2012). É possível compreender que a educação profissional e tecnológica - com vistas à tecnologia enquanto mera mediação entre ciência e produção, sem problematizar a natureza dessa mediação que se construiu historicamente - pouco ou nada pode avançar quanto aos ditames da empregabilidade via desenvolvimento de competências dos estudantes.

\section{CONSIDERAÇõES FINAIS}

O desenvolvimento tecnológico no contexto da expansão dos setores produtivos, ocorridos a partir dos anos de 1990, tem requerido do poder público algumas respostas, com ênfase em políticas educacionais, com vistas à formação profissional para a atuação numa sociedade cada vez mais complexa e cambiante. Assim, o poder público tem sido demandado para a criação, implementação e avaliação de políticas educacionais eficazes, direcionadas à formação do estudante para o mundo do trabalho, bem como o seu preparo para o seu futuro profissional. No entanto, evidencia-se a necessidade de uma formação pautada por princípios críticos-reflexivos que contribua com a formação autônoma e emancipatória dos indivíduos e das coletividades.

Para Souza (2006), no que se refere aos países em desenvolvimento e de democracia recente, a maioria deles, sobretudo os países da América Latina, incluindo o Brasil, tem tido dificuldade para estabelecer coalizões no âmbito das políticas públicas que direcionem ações capazes de equacionar o desenvolvimento econômico com a inclusão social. A criação de agenda orientada à resolução de problemas sociais - no tocante às decisões direcionadas para a elaboração e implementação - muitas vezes, é amplamente caracterizada por conflitos e posicionamento conservadores, o que impede a construção de uma agenda que contemple os interesses holísticos da sociedade.

O aumento quantitativo da oferta de educação profissional e tecnológica vem sendo objeto constante de discussão e reflexão, no sentido de estabelecer mecanismos de oferta e medidas de avaliação da formação 
profissional, objetivando respostas satisfatórias nos quesitos de qualidade, tanto para as comunidades inseridas no meio social, quanto para o setor produtivo. A gestão, planejamento e avaliação de instituições de ensino de educação profissional e tecnológica tem sido um dos pontos enfatizados para a mensuração da qualidade dos cursos ministrados pelas instituições de ensino. Essa mensuração tem sua ocorrência, de maneira generalizada, a partir de indicadores de empregabilidade. Contudo, salienta-se que a expansão e a sustentabilidade das escolas técnicas e tecnológicas e a inserção do jovem em todos os aspectos da vida social, continuam distantes de uma resposta satisfatória.

A ligação direta que se faz entre emprego e aumento de ofertas de vagas no ensino técnico e tecnológico precisa ser sempre avaliada. A problematização da formação integrada em todos os níveis e modalidades de ensino, o debate amplo sobre a legislação trabalhista, as estratégias claras para certificação e regulamentação profissional, o apoio a pequenos e microempreendedores, o compromisso com empreendimentos de base tecnológica, a consolidação de formação de trabalhadores pelos próprios trabalhadores são algumas das ações que, interligadas, podem, de algum modo, fundamentar, entre outras necessidades, as políticas de geração de emprego e renda (FRIGOTTO, 1999; 2001).

Ou seja, ainda que se deva defender a educação como fator importante no progresso e desenvolvimento de uma sociedade país ou região, há que se considerar a interdependência de vários de fatores que requerem dos agentes públicos tomadas de decisões que contemplem a realidade multidimensional e as demandas não só de caráter econômico, mas, também, político e social.

De qualquer forma, é necessário ampliar os estudos e reflexões sobre a ênfase no investimento individual e coletivo em formação profissional como elemento fundamental para o aumento da empregabilidade. É preciso, igualmente, avaliar os limites e as possibilidades de se investir em uma formação de qualidade, sem as perspectivas de obtenção de boa oportunidade no mercado de trabaIho, que seja condizente com a sua capacitação profissional. Junto aos estudos sobre empregabilidade há que se problematizar se qualificação profissional diz respeito às condições necessárias de trabalho decente. O que se pode concluir é que investir em capacitação é fator relevante para se alcançar a empregabilidade, porém, não é suficiente, nem a empregabilidade pode sintetizar as possibilidades do exercício de uma cidadania plena.

Além de estudos de natureza qualitativa e quantitativa, para mapear e analisar conceitos e percepções, há muito que se avançar no que concerne ao estudo com egressos de cursos nas mais variadas modalidades e certificações. Compreende-se que a questão é mais epistemológica que metodológica à medida que é necessário pensar como se tem concebido as relações entre educação e trabalho.

\section{REFERÊNCIAS}

ARCANJO, C. R. O. de; OLIVEIRA, S. R. de; BATISTA, S. S. S.; FREIRE, E.; ALMEIDA, B. I. Políticas públicas e a formação para o mundo do trabalho: contribuições para os estudos em Educação Profissional e Tecnológica. X Workshop de pós-graduação e pesquisa. São Paulo: CEETEPS, 2015. Disponível em: <http://www.cps.sp.gov.br/pos-graduacao/workshop-de-pos-graduacao-e-pesquisa/010-workshop-2015/workshop/trabalhos/Educacao_Pro fissional/Polit_Educ_Profissional/Polit_Publicas_e_a form_mundo_trab.pdf> Acesso em: 07 set. 2016.

BALASSIANO, M.; SEABRA, A. A.; LEMOS, A. H. Escolaridade, Salários e Empregabilidade: Tem Razão a Teoria do Capital Humano? Revista de Administração Contemporânea, v. 9, n. 4, Out./Dez. 2005: 31-52. Disponível em: < http://www.scielo.br/pdf/rac/v9n4/v9n4a03 > Acesso em: 08 nov. 2016. 
BATISTA, Roberto L. A ideologia da nova educação profissional no contexto da reestruturação produtiva. São Paulo: Cultura Acadêmica, 2011.

BETTIOL, T. M. A empregabilidade como garantia de cidadania na educação da juventude na escola pública. IX Congresso Nacional de Educação - EDUCERE III Encontro Sul Brasileiro de Pedagogia. Curitiba: PUCPR, 26 a 29 de outubro de 2009. Disponível em: <http://www.pucpr. br/eventos>. Acesso em: 27 dez. 2016.

BRASIL. Ministério da Educação. Decreto n² 2.208, de 17 de abril de 1997. Regulamenta o Parágrafo $2^{\circ}$ art. 36 e os arts. 39 a 42 da Lei $n^{\circ}$ 9.394, de 20 de dezembro de 1996, que estabelece as diretrizes e bases da educação profissional. Diário Oficial da União, Brasília, 1997.

. Decreto $\mathrm{n}^{\circ}$ 5.154, de 23 de julho de 2004. Regulamenta o parágrafo $2^{\circ}$ art. 36 e os arts. 39 a 41 da Lei $n^{\circ}$ 9.394, de 20 de dezembro de 1996, que estabelece as diretrizes e bases da educação nacional e dá outras providências. Diário Oficial da União, Brasília, 2004.

. Ministério da Educação. Resolução CNE/CEB nº 2, de 30 de janeiro de 2012. Diretrizes Curriculares Nacionais para o Ensino Médio. Brasília. DF, 2012.

BRUNO, Lúcia. Educação, qualificação e desenvolvimento econômico. In: BRUNO, Lúcia (Org.) Educação e trabalho no capitalismo contemporâneo (leituras selecionadas). São Paulo: Atlas, 1996.

CORDÃO, F. A. Desafios das diretrizes curriculares nacionais para a educação profissional. Boletim Técnico do SENAC. Rio de Janeiro, v. 39, n.2, p.26-47, maio/ago., 2013.

DELUIZ, D. O Modelo das competências profissionais no mundo do trabalho e na educação: implicações para o currículo. Boletim Técnico do SENAC, Rio de Janeiro, v.27, n.3, p.13-25, set./ dez. 2001.

DIAS, Vagno E. M. A educação integrada e a profissionalização no ensino médio. Tese (Doutorado em Educação). Centro de Educação e Ciências Humanas. Programa de Pós-Graduação em Educação. São Carlos: UFSCar, 2015. 239 p.

FRIGOTO, G. Educação e trabalho: bases para debater a educação profissional emancipadora. Revista Perspectiva. Florianópolis, v.19, n 1, p.71-87, jan-jun 2001.

FRIGOTO, G. A relação da educação profissional e tecnológica com a universalização da educação básica. Educação \& Sociedade. Campinas, vol. 28, n. 100 - Especial, p.1129-1152, out. 2007.

. Globalização e Crise do emprego: mistificações e perspectivas da formação técnico-profissional. Boletim Técnico do SENAC, v.25, n2, mar-ago 1999.

HELAL, D. H. Flexibilização organizacional e empregabilidade individual: proposição de um modelo explicativo. Cadernos EBAPE. BR - Volume III - Número 1 - Março 2005. Disponível em: <http://www.scielo.br/pdf/cebape/v3n1/v3n1a06.pdf.> Acesso em: 08 jan. 2017.

HELAL, D. H.; NEVES, J. A.; FERNANDES, D. C. Empregabilidade Gerencial no Brasil. Revista de Administração Contemporânea-Eletrônica, v. 1, n. 2, art. 1, p. 1-19, mai/ago. 2007. Disponível em: $<$ http://www.anpad.org.br/periodicos/>. Acesso em: 08 jan. 2017.

HELAL, D. H.; ROCHA, M. O discurso da empregabilidade: o que pensam a academia e o mundo empresarial. Cadernos EBAPE.BR, v. 9, n 1, artigo 8, p. 139-154. Rio de Janeiro, Mar. 2011. Disponível em: <http://www.scielo.br/scielo >. Acesso em: 08 jan. 2017. 
LEMOS, A. H. C.; DUBEUX, V. J. C.; SOARES PINTO, M. C. Educação, empregabilidade e mobilidade social: convergências e divergências. Cadernos EBAPE.BR. v. 7, $n^{\circ}$ 2, artigo 8, Rio de Janeiro, p. 383-384. Jun. 2009.

LOPONTE, L. N. Educação profissional: um estudo da lei e implantação da reforma do ensino técnico e suas decorrências no CEFET-RS (1997-2004). Dissertação (Mestrado em Educação). Programa de Estudos Pós-Graduados em Educação: História, Política e Sociedade. Pontifícia Universidade Católica de São Paulo. São Paulo: PUCSP, 2006.

. Juventude e educação profissional: Um estudo com os alunos do IFSP. Tese (Doutorado em Educação). Programa de Estudos Pós-Graduados em Educação: História, Política e Sociedade. Pontifícia Universidade Católica de São Paulo. São Paulo: PUCSP, 2010.

MACHADO, G. R. Um estudo do perfil demandado pelo mercado de trabalho para $s$ alunos egressos da Escola Técnica da Universidade Federal do Rio Grande do Sul. Dissertação (Mestrado Profissionalizante em Engenharia de Produção). Escola de Engenharia. Universidade Federal do Rio Grande do Sul. Porto Alegre: UFRGS, 2002. Disponível em: <https://www.lume.ufrgs. br/ bitstream/handle> Acesso em: 14 jul. 2016.

. Perfil do egresso da Universidade Federal do Rio Grande do Sul. Tese (Doutorado em Educação). Programa de Pós-Graduação em Educação, Faculdade de Educação. Universidade Federal do Rio Grande do Sul. Porto Alegre: UFRGS, 2010. Disponível em: <https://www.lume. ufrgs.br/bitstream/ handle> Acesso em: 16 nov. 2016.

MARCIEL, C. M. O ensino técnico e a empregabilidade do jovem no Brasil. Universidade Federal do Rio de Janeiro. Edu Pro: C e T, Brasília, 1(1): p. 99-106, jul-dez, 2006.

MINISTÉRIO DA EDUCAÇÃO - MEC. Proposta em discussão. Políticas Públicas para a Educação Profissional e Tecnológica. Brasília, MEC/SETEC, 2004.

OLIVEIRA, Cláudio L. V. de O. et. al. Programa de Extensão e Cultura da Faculdade de Tecnologia De Jundiaí (2015). Revista Eletrônica de Tecnologia e Cultura. São Paulo, Edição 18a , p. 128140, Abril de 2016. Disponível em: http://201.55.32.167/retc/index.php/RETC/article/view/312/pdf. Acesso em: 09 jul. 2017.

OLIVEIRA, Ramon de. O Banco Mundial e a educação profissional. Boletim Técnico do SENAC. São Paulo, v. 27, n.2, 2001.

OLIVEIRA, S. R. Empregabilidade, Cidadania e Juventude: um estudo sobre os egressos do ensino técnico integrado ao médio do Instituto Federal de Educação, Ciência e Tecnologia de São Paulo (IFSP - Campus SP) entre 2011-2015. 140 f. Dissertação (Mestrado Profissional em Gestão e Desenvolvimento da Educação Profissional). Centro Estadual de Educação Tecnológica Paula Souza. São Paulo: CEETEPS, 2017.

OLIVEIRA, F. J.; MAÑAS, A.V. Tecnologia, trabalho e desemprego um conflito social. São Paulo: Érica, 2004.

PETEROSSI, G. H. Subsídios ao estudo da educação profissional e tecnológica. Coleção fundamentos e práticas da educação profissional e tecnológica. SP. São Paulo: CEETEPS, 2014.

SAMPAIO, M. V. D; LOPES, R. L.; THOMAZ, S. M.; APOLINÁRIO, V. Empregabilidade e perfil da inserção de egressos do IFRN no mercado de trabalho. VIII CONNEPI, Salvador-Bahia, 2013.

SOUZA, H. G. Política de educação profissional e tecnológica e desenvolvimento territorial: análise do Instituto Federal Baiano no contexto do semiárido da Bahia, Brasil. Tese (Doutorado 
em Educação) Faculdade de Educação. Universidade Estadual de Campinas. Campinas-SP: UNICAMP, 2015.

SOUZA, S. Políticas públicas: uma revisão da literatura. Revista Sociologias. Porto Alegre, ano 8, n 16 , Jul-dez, 2006, p.20-45.

\section{Salvador Rodrigues de Oliveira}

Mestre em Educação Profissional. Centro Estadual de Educação Tecnológica Paula Souza. Professor no Instituto Federal de Educação, Ciência e Tecnologia de São Paulo - IFSP - Campus SP. São Paulo. Brasil. E-mail: Salvador.r.oliveira@gmail.com

\section{Sueli Soares dos Santos Batista}

Pós-doutorado no Departamento de História e Filosofia da Educação da Faculdade de Educação da Unicamp. Professora no Mestrado Profissional do Centro Estadual de Educação Tecnológica Paula Souza (CEETEPS). São Paulo. Brasil. E-mail: suelissbatista@uol.com.br

Submetido em: 14-7-2017

Aceito em: 28-11-2017 